https://helda.helsinki.fi

\title{
From community to assemblage? : ICT provides a site for inclusion and exclusion in the global south
}

Kivikuru, Ullamaija

2019-01

Kivikuru , U 2019 , ' From community to assemblage? ICT provides a site for inclusion and exclusion in the global south ', Journal of International Communication , vol. 25 , no. 1 , pp. 49-68 . https://doi.org/10.1080/13216597.2018.1544163

http://hdl.handle.net/10138/317732

https://doi.org/10.1080/13216597.2018.1544163

unspecified

acceptedVersion

Downloaded from Helda, University of Helsinki institutional repository.

This is an electronic reprint of the original article.

This reprint may differ from the original in pagination and typographic detail.

Please cite the original version. 
Ullamaija Kivikuru

(ullamaija.kivikuru@helsinki.fi)

University of Helsinki

Finland

\section{From community to assemblage?}

\section{ICT provides a site for inclusion and exclusion in the Global South}

\section{Abstract}

The role of information and communication technology (ICT) in development has been discussed from two distinctly different perspectives: some researchers and activists view it as a means for opening new alleys for facilitation of development and democracy, while others assess it counterproductive. Further, it has been emphasized that people in cities and rural areas meet ICT in different ways, as do people with wealth and education compared to poor people.

In Africa, Kenya has declared itself as ICT hub, and indeed, two-thirds of the population have today access to the internet. The state has emphasized ICT in promoting services; attitudes toward communication policies and freedom of expression are far more reserved.

The article discusses ICT and development via the filter of assemblage, a key concept in the ontological framework developed by Deleuze and Guattari (2004/1980). They draw their framework from dynamic systems theory, emphasizing fluidity as well as micro- and macro-level dichotomies. In this article, assemblage is used as a metaphor for ICT domestication in Kenya. When communities based on sharing and consistent social order meet new technology, the change goes far deeper than to improved services. The basic difference might be the fact that a community is constructed on cultural ties developed over time, strengthening immobility and stability, while an assemblage is characterized with mobility and fluidity. Thus, a system of values, hierarchies and inherited traditions is challenged, mixed with 'new' problems brought by individualised behaviour. 
In recent years, sophisticated approaches have been produced to analyse not only the availability of ICT-based information but also the effects of its emergence in the media ecology of developing societies. The concept of media ecology originates from Harold Innis' (1951) and Marshall McLuhan's (Carpenter \& McLuhan, 1960) works covering the study of media, technology and communication and how they affect human environments. Several authorities have drawn a general conclusion from these very different studies (Chao \& et al., 2017; Shao \& Wang, 2017; Obijiofor, Murray, \& Singh, 2017). They found that a few years after the celebrated introduction of new ICT-based channels of expression, the complexities involved can be recognized. The domestication of ICT has often tended to turn into a jerky process. There is more information available and there are more chances to express one's views in public, but the collision with existing local politics and ideology, media establishments and cultural norms may introduce elements of both inclusion and exclusion into the 'new' media ecology.

\section{The case of Kenya}

Kenya is simultaneously a representative example of recent communication development in Africa and an exception. The weak political institutions and externally-oriented economic system, inherited from colonial rule, are recognized not only in Kenya but in many other African countries. Infrastructures are weak, and ethnic contradictions are strong and deeply intertwined with politics. The state has been reluctant to study the imagined histories in Kenyan media discourse; consequently, the history of independent Kenya is characterised by little consensus on historical events (Muthongo, 2015). On the other hand, the state is reasonably stable, and the country has avoided military rule, social instability and social collapse. However, the violent political clashes after the 2007 elections and the bloody attacks in Westgate (in 2013) and Garissa (in 2015) indicate how delicate social balance is in a transitional democracy (Hornsby, 2013, pp. 5-18). Most recently, the dramatic processes around the presidential elections in 2017 indicate that the political system cannot easily solve complex, history based social contradictions.

Kenya has repeatedly been named as a front-runner in sub-Saharan Africa's internet access and connectivity. Indeed, the debated African mobile phone revolution is strongly present in Kenya. In 2002, there were just two mobile phones for every 100 of the country's 38 million people. In the next five years, the number of mobile phones increased from one million to 10 million, and their popularity has accelerated since then. Today, the mobile phone penetration rate has reached 88 per cent, and more than half of these are smartphones (Communications Authority in Kenya, 2017). Kenya's internet penetration has now reached almost 78 per cent of the population, while the average rate for the whole of Africa remains under 30 per cent

(http://www.internetworldstats.com/stats1.htm).

The M-Pesa banking system, based on the mobile phone, is the flagship project of Kenyan ICT progress. It was developed and introduced by private telecommunication companies. M-Pesa has been a highly successful project. Even illiterate rural women can use it, thus giving themselves slight economic independence. Another flagship has been the Huduma Centres. These are onestop shops in the counties to ease access to and payment for government services electronically. Today there is a Huduma Centre in every county capital in Kenya, and more and more public services have been attached to its supply. Thus, the government has been brought closer to the citizens, but of course, the services do not much help village people living far from county capitals.

\section{Assemblage as a media ecology marker}


Assemblage is a concept with a variety of meanings in several fields, for example, in philosophy, arts, archaeology and palaeontology. This philosophical approach refers to an ontological framework developed by Deleuze and Guattari and originally presented in their book $A$ Thousand Plateaus (1980). Assemblage theory provides a bottom-up framework for analysing social complexity by emphasising fluidity, exchangeability and multiple functionalities. The relationships of component parts are not stable and fixed. In a philosophical sense, assemblage originally stems from the French word agencement. Critics (among others, Phillips, 2006) have said that through narrow, literal English translations, the French term has often been interpreted in a narrow, misleading way. Deleuze and Guattari did not use the concept systematically. Several philosophers, including DeLanda (2006) and Packer and Wiley (2012), later used the concept with slightly varying meanings, but the substance remains the same. Assemblage is a way to describe a bottom-up model of mobility and networking. The formation of connections and distribution of focus is crossed through the 'body, brain, tool, and environment' (Packer \& Wiley, 2012), each collaborating and competing for attention while being given meaning.

As shown above, this somewhat obscure concept easily leads to complex philosophical considerations. However, in this text, it is mainly used as a metaphor for continuous social mobility and the creation and discarding of hierarchies. According to Deleuze and Guattari, the constellation of new hierarchies includes some existing elements but leaves out others. In this paper, the idea of continuous movement and inclusive/exclusive constellations is central. Such processes take place in various layers of society and may lead to unexpected changes.

Assemblage theory offers an intriguing challenge to conventional configurations of the relations between parts and wholes. It argues that wholes are constructed by the coming together of separate and individual parts. From the perspective of assemblage theory, parts can function autonomously, but they can also become part of assembled wholes, be removed from them, and then become part of further yet-to-be-assembled 'togethers.'

This text will elaborate on the mechanisms of assemblage that have evolved in the present-day media ecology of Kenya and reflect on the social changes which these mechanisms might cause. I will discuss the elements that make up the Kenyan mediascape, a term coined by Arjun Appadurai (1996). It refers to the electronic and print media in global cultural flows. The mediascape indexes the electronic capabilities of production and dissemination and the images of the world created by these media. In this paper, the concept of mediascape is extended to cover all channels of information distribution in society. The assumption is that today, online services providing information to citizens cooperate in the process of forming images of the world.

The difference between mediascape and media ecology is, in my vocabulary, that the mediascape does not carry the same moral and normative nuances as media ecology. Media ecology tends to suggest how things should be in order to promote a balanced media atmosphere. Consequently, I start with the mediascape and proceed to considerations of the media ecology.

\section{Mediascape evidence}

Kenya has been an early-bird in Africa with its ICT emphasis, but its progress has been financed to a large extent by external sources. There are dozens of government policy blueprints about ICT planning, many of them describing ICT as a phenomenon resembling electricity and taking the same form all over the world. 
According to policy experts (e.g. Gekao, November 2015), the selection of ICT as an emphasis area for development around the turn of the century in Kenya was both a deliberate measure and a necessity; the population was growing fast, agriculture had not progressed according to plan and tourism did not appear as a major branch of income gathering (Kivikuru, 2017). It may well be that the selection of ICT as a major emphasis area in social planning was based on a search for the common good, but it can also be a fashionable choice, a popular theme that had been on the agenda of the International Telecommunications Union (ITU), UNESCO, the African Union (AU) and several foreign donors.

\section{Policies: From electricity to food?}

In Kenya, ICT policymaking has been a distinctly top-down process. The point of departure has not been 'ICT for development', although motivations implicitly carry some developmental aspects, as do all social planning in developing countries. An indication of the government's motivation to promote ICT development is the Kenya National ICT Masterplan (2013/14 - 2017/18) covering the whole country. It was approved in 2014 and is constructed on three pillars: human resources as a prerequisite for ICT progress, development of ICT infrastructure, and the goal of ensuring every Kenyan access to public information. The desired outcomes are the availability of a high-quality workforce for business and an 'ICT literate population capable of exploiting ICT products and services for improved quality of life' (Masterplan, 2014, p. 48).

Thus, the citizens are included in the process, but the strategies to reach the goals for technology or workforce qualifications are considerably more detailed than the goals for ICT literacy for the public. Perhaps the most ambitious part of Kenyan ICT policies is the plan to provide digital learning in every school in the country, from primary schools to universities (The Digital Learning Programme, $D L P^{1}$ ), requiring the education of more than 300,000 teachers and the acquisition of more than a million computers by 2019.

Kenyan ICT experts are the first to complain about poor implementation of the policies expressed in the Masterplan. They see a lack of funds as the main reason, but poor administration is also criticised. The huge DLP plan has met a variety of problems, not all of which are explicable by the scarcity of funds. However, based on the empirical evidence (Kivikuru, 2017), domestication appears to be receiving now more attention from the experts implementing Kenyan ICT policies. The Kenyan digital hub is reaching a new crossroads phase after some 20 years of planning. The Masterplan with its fixed objectives is being partly replaced by softer and more flexible plans. As an expert says (Gekao, November 2015), ICT is no longer viewed as comparable with electricity but with food - needed everywhere, but taking different forms in different places. The service sector is strongly promoted, while freedom of expression and citizen rights are dealt with carefully by decision-makers. So far, ICT policies have mainly focused on public access alone, not on possibilities and obstacles of building up social capital (Proenza, 2015, pp. 400-407).

\section{Media: Increase of channels and mobile-based practices}

The Bill of Rights, a special chapter in the new constitution, was confirmed in 2010. It emphasizes freedom of expression and media freedom. However, the dialectic between freedom and responsibility in media performance has been difficult to find in Kenya after it gained independence in 1963 and after the transfer to a multi-party system in 1992. Although the country has enjoyed economic growth in recent decades, the media market is relatively small. However, as

\footnotetext{
${ }^{1}$ https://worldteacheraid.org/digital-learning-programme-in-kenya-schools/
} 
happened in South Africa, the change from terrestrial to digital broadcasting technology is changing radio and television structures rapidly by promoting television and reducing radio audiences (The State of the Media in Kenya, 2014).

Major media companies have their online platforms. Although there are significant differences in the level of sophistication of websites and the amount of traffic on each, the mere fact that they have an online presence demonstrates their appreciation of technological advancements and a desire to capture and retain the younger audiences (The State of the Media in Kenya, 2014).

Mobile phones have become a key component in news collection, investigative journalism and journalistic activities. For example, the mobile phone is an important companion for journalists keen to keep in touch with their newsrooms and editors while on assignment. For a television journalist operating outside Nairobi (Eldoret), new technology has changed everything. The work of a Kenyan journalist today more resembles the work of television professionals in industrialised countries, and increased mobility allows more attention to grassroots efforts. However, the gatekeepers in Nairobi are not always motivated to broadcast reports from distant villages. The use of new technologies in journalistic practice seems to reflect national contexts and circumstances. Even as journalists celebrate new technologies, they still face the same professional limitations as before (Kivikuru, 2017).

Newspaper circulations have been decreasing in recent years. The newspaper clearly remains a medium for the urban elites, also papers with somewhat more populist news values (The Star, The Nairobian); there is no clear evidence of tabloidization. An analysis of newspaper content carried out by the author suggests that the target audiences are distinctly urban elite groups interested in party politics. $^{2}$

During the 50 years of independence, the basic motive of Kenyan media policies has been to support those managing the state rather than to provide the public with relevant information (Ugangu, 2015). However, the Kenyan media have undoubtedly gradually opened themselves to more independent voices. The lively debates in Kenya's print media have created envy and admiration among its neighbours in East Africa, many of whom have a far more mixed history of media freedom. However, Binyavanga Wainaina $(2008$, p. 17) has described present-day Kenyan journalism in the following way: 'Our media is obsessed with the soap opera of political characters. So Kenya is really just a theatre-screen where we watch a few people play drama games on stage, and clap, or cry or laugh.' Kenyan media publicity tends to be an elite exercise. Today, part of the clapping or laughing audience operates online, but citizens remain as an audience. With the exception of morning radio phone-ins, the ordinary people rarely participate in debates about public issues.

The author's own rough quantitative-qualitative content analysis supports Wainaina's cynical comments. In November 2016, almost four-fifths of the Daily Nation's (78\%) and The Standard's (76\%) daily general news content dealt with national politics, mainly covering issues related to the general elections scheduled for August 8, 2017 or corruption cases that often had links with both politics and economy. Only three newspaper issues (of a total of 20) carried a leading front-page

\footnotetext{
${ }^{2}$ Issues of Daily Nation, The Standard November 17-26, 2016; Daily Nation, The Standard in November 18-24, 2015; issues of The Star and The Nairobian November 2016. The quantitative analysis was based on headline counting, not volumes.
} 
story covering anything other than national politics and/or corruption. The style of reporting was exclusive, not motivating readers to debate and discussion. The reporting was strongly personcentred, the style remaining neutral but keeping the big names on the agenda day after day. Explicit or implicit details of the behaviour of the persons described revealed their ethnic connections by reporting on certain traditions, colours and scarfs, and pictures were essential markers of this. Interestingly, the style of reporting in the online platforms of the papers studied was distinctly more discussion-oriented than in the mother media, and there was more countylevel news, although most of this was linked to the coming elections.

In the previous year (November 2015), there was somewhat less reporting of national politics, which accounted for 63 per cent of The Nation's and 67 per cent of The Standard's general news content. Both papers regularly published local (county) news, but as modest, minimal-size pieces mainly covering accidents, diseases, weather problems, oddities and local politics. The local press is almost non-existent.

A recent study (Ireri et al, 2017) discusses the agenda-setting power of the two main newspapers' ability to influence public opinion about corruption, devolution, economic crisis, insecurity, poverty and unemployment. According to this quantitative study, the two papers covered the six studied themes in a strikingly similar manner but had a marginal influence on the Kenyan public about the themes. The papers seem to lead a life of their own, distant from the general public.

Radio is the most inclusive of all the main media. The number of phone-ins to any national station is high, especially during the morning programmes, and political issues are also debated. The various television channels present regular news bulletins with a few thematic debates on national politics every week, but most of programming is oriented toward entertainment. Reality television has found its place on public and private television channels, but perhaps even stronger is the tendency to support consumerism and middle-class values (e.g. cooking, cars, travel and wedding programmes). The news bulletins on both radio and television adopt similar criteria to those of the newspapers but with less focus on politics. Local radio stations have a strong local emphasis, but local coverage is limited on the national stations.

Sports reporting in all the major media gave its greatest attention to national-level sports, personalities and events, although British sports received continuous attention. Little attention was given to international issues during the periods studied. What coverage there was mainly comprised news from East African neighbours, international agencies and business information from the Western world.

\section{Media policies: One step behind}

The official media policy and the media policies adopted by the large media companies display ambivalence and contradictions. These policies are shaped by colonial histories, postcolonial realities and the post-independence development agendas. The older state-inspired normative arguments, such as the need for a developmentalist press, still influence policy today. Changes in the political space, therefore, shift media policy in a direction that supports the political establishment's objectives. Media policies embrace Kenya's customs and aspirations, such as attitudes to ethnicity, religious and cultural differences and the crafting of a national identity. However, the most decisive factor in the Kenyan media system remains unchanged. Politics is decisive (Ugangu, 2015). 
The most interesting phenomenon so far may be that public ICT policies and ICT-based media changes have developed separately. Formally, ICT and media matters are dealt with by the same ministry (the Ministry of Information, Communications and Technology), but they have been developed separately by two different state departments between which there is little cooperation. Contradictions arise in the activities on the borderline between ICT and conventional media. The most dramatic contradiction appeared in 2015 when the digital migration of television broadcasting was being debated. The situation became so difficult that the three main private media houses (Nation Media Group, Standard Group and Royal Media Services) went off air for a few weeks in protest. One of the benefits of digital migration is the increased variety of channels, which in turn means more content for subscribers. Digital signals take less bandwidth, and this has allowed for the growth of more channels in Kenya. About 60 per cent of the Kenyan population is covered by the digital signal (Communications Authority of Kenya).

\section{Media consumption: The rise of television}

According to one survey (Ipsos Synovate, 2011), radio (95\% daily) is still the main media source of the Kenyan population. An average person listens to three stations weekly, mainly Swahili language stations. Radio is used daily as the primary source of news, music and entertainment. The average television viewer watches up to three channels in a week, but spends far less time watching television than listening to radio. During prime time, most television time is spent watching soap operas and news. About 650,000 Kenyans watch television weekly, while the equivalent figure for radio listeners is about 4.5 million (The State of the Media in Kenya, 2014).

Many newspaper readers do not purchase their own copy but rely on a copy from a household member or from the office. The key sections of interest in newspapers are local news, sports and international news (Ipsos Synovate, 2011). There seems to be a contradiction between the strong bias towards national politics of newspaper content and the demand for local news.

The mediascape in Kenya is changing; television is becoming more popular, competing with radio in popularity in towns. In 2013-2014, television viewing grew by 82 per cent, while the equivalent figure for radio was only 20 per cent. The main reasons are the change to digital technology and, as a consequence, an increase in free-of-charge television channels. Radio very often uses regional or vernacular languages, while television is strongly oriented to the English language and imported programmes and formats. However, digital migration has now enabled the emergence of locallanguage television channels (e.g. KASS TV, 3 Stones), and they have fast become popular (The State of the Media in Kenya, 2014). Thus, the language - and locality as an implicit factor appears as a significant reason for a medium's popularity.

It can be assumed that the position of the medium of the majority - radio - has become at least somewhat weaker, although radio access has improved because of digitalization and mobile phone radio listening. The big, strong radio stations have lost audiences, while small, vernacularlanguage stations have kept theirs (The State of the Media in Kenya, 2014). These vernacularlanguage stations have raised political concerns at the national level where it has been argued that the delicate ethnic balance may be at stake (Ogola, 2015). For the same reason, many experts are hesitant about the Ministry of Information's plan to introduce county-level ICT services in the dominant local language (Kivikuru, 2017).

Among Kenyan youth, social media are the primary source of news and information (60\% daily), while television (28\%) is the second (Wangari, 2017). However, the credibility of newspapers remains high among well-educated youngsters. In focus group discussions with Moi University 
students (November 2015), Master's students in particular emphasized the importance of the print media, although their own daily media use did not regularly include newspapers. ${ }^{3}$ These students seemed to make a distinction between the values of their professional lives, which included newspapers, and their own everyday practise that circled around social media. They emphasized that newspapers are the most credible medium. They also referred often to radio, but these young adults were not at all interested in television.

\section{Social media: Limited activism}

About 20 million Kenyans have access to the internet, but few of them use it for discussions and those that do it are mainly based on cities. WhatsApp and Facebook rank among the most-used platforms (Wangari, 2017). Young urban dwellers have also found in Facebook a platform that can give them access to political information in formats that are appealing to them. They have been able to mobilise themselves online and push for a political agenda (Otiene \& Mukhiongo, 2013). Certain protests have become symbols of social media culture and online resistance in Kenya. These new forms of resistance have created new avenues of mobilization and protest. Social media sites include 'Occupy parliament', 'My dress my choice' and 'Occupy playground' ${ }^{4}$

There is evidence that the online space is becoming increasingly institutionalised as a platform for popular expression, while the mainstream media's regime tends to close its ears to outsider voices (Ogola, 2015). The new media thus afford users - mainly young people in urban centres - the opportunity to mobilise protests and lobby groups, but they also alienate those segments of society that do not have access to social media.

\section{Discussion: From static to fluid?}

A superficial review suggests that although the Kenyan mediascape has not yet radically changed with the introduction of the ICT, there are several change processes emerging in parallel on various levels, all carrying an include/exclude element. The components of these processes include both material factors and meaningful expressions. These processes may appear to lack clear boundaries, but they are still amenable to analysis and study. In a society that cherishes social stability, aspects of these emerging processes may appear worrying and perhaps even alarming. In the following discussion, some of these aspects will be discussed against the background metaphor of assemblage.

\section{Policy implementation moulds culture}

Donors and financiers have been interested in the promotion of ICT in Kenya, but naturally have their own ideas about the shape and direction of Kenya's domestic development policies.

Researchers (e.g. Etta, 2005) claim that African politics and policymaking are less home-grown today than in the 1960s and 1970s. The main reason for the lack of independent politics is the

\footnotetext{
${ }^{3}$ Four focus groups comprising a total of 22 Moi University students participated in these discussions in midNovember 2015.

${ }^{4}$ The 'Occupy parliament' movement came about after members of parliament raised their salaries, the dress movement after three women accused of indecent dressing were stripped on the streets of Nairobi and the playground movement after a school playground in Nairobi was grabbed by a developer who intended to use the land as a car park.
} 
Structural Adjustment Programmes (SAPs) implemented in African countries in the 1970s and 1980s. The SAPs of the World Bank and the International Monetary Fund (IMF) have tailored social planning in Africa. Donors also make their voices heard. 'In no other of contemporary endeavour is the influence of donors more evident than in ICT policy planning. Most policy work [...] has been or is being funded by donors', says Etta $(2005$, p. 9). The danger exists that modes of ICT that do not strongly support democracy and citizen rights are promoted simply because these dimensions have proved useful in the industrialised world. ICT thus tends to be interpreted as a phenomenon like electricity, the same everywhere and taking the same mode in any society.

The generalised 'common good' ideology presented in the policy documents about ICT is rational only if the ICT administration is assumed to be a consistent, mainly technical process. Elements linked to democracy and citizen well-being are mentioned, although these dimensions remain abstract and diffuse. For example, nothing bad can be said about the digital literacy goal, meant to be completed by digitalizing the whole school system. However, this goal, as well as several others, does not seem to be aligned with the realities of the society it is meant to be implemented in.

The choice of emphasis areas shows the aim of domestication in education, services and capacity building. However, the volume of the challenges accepted, especially in eEducation, is unrealistic. Even when implemented in stages, training the teachers and acquiring the equipment is a huge challenge. As already seen, the digitalization goal has widened the gap between private and public schools and increased inequality between wealthy and poor counties. Although the project deadline is only two years away, as few as between five and seven per cent of Kenyan public primary schools have the equipment, curricula and competent teachers for digital education. In addition, scandals have complicated the process, as often happens in Kenya when big sums of money are involved. The inclusion/exclusion dimension is biased towards exclusion and increased imbalance among the population.

The services objective has been more successful, especially in the establishment of Huduma Centres, although the range of their activities is limited, sharpening the difference between urban and rural areas. Undoubtedly, the aim of cutting bureaucracy and corruption is relevant, and it can be assumed that online services and increased transparency will strengthen people's interest in public matters. In this way, a stronger inclusion element is dominant. Increased connectedness has been found in a similar project in rural Malaysia (Alias et al., 2015 pp. 233-263).

Ironically, the private sector (Vodafone) has been extremely successful with M-Pesa. In less than 10 years, this branchless banking service has become the most successful mobile-phone-based financial service in the developing world. It has not only expanded the financial freedom of grassroots people but also meant a clear change for the better in the everyday life of citizens and above all, of women. However, M-Pesa may work to erode the functional norms of some communities. Traditional culture-based behaviour, for example, makes issues related to authority, privacy and trust complicated. Communities have been driven to the stage of liminality (Turner, 1974), to a threshold stage of uncertainty. Social hierarchies may be reversed or temporarily dissolved, continuity of tradition may become uncertain and future outcomes once taken for granted may be thrown into doubt. Thus, there is a looming possibility that the stability of local communities may be shaken.

At the grassroots level, ICT implementation meets cultural problems. There is already a cultural divide in Kenya, opening doors for some but also breaking down old culture-based values and practices. When communities based on sharing and a consistent social order meet new 
technology, the changes go far deeper than the value-free interaction of humans and machines. A system of values, hierarchies and inherited traditions is challenged by the new problems brought by individualised behaviour. For example, respect for age, seniority and gender difference is shaken. Problems are caused by the combination of old and new practices, such as the difficulties of ensuring privacy in shared telephone use. Gender differences and age hierarchies do not disappear, but their profiles change as people are more and more tied to technology that they cannot afford. Inequalities do not disappear with M-Pesa, and they may even be exacerbated.

M-Pesa has created micro and macro dichotomies, which Leah Komen $(2016,2015)$ has studied. Based on her ethnographic interviews in Marakwet in western Kenya, Komen views mobile money as a socio-economic assemblage. According to her, M-Pesa should not to be studied as a mobile phone success story or simply as an application enabling the transfer of money. Rather, it should be seen as a multi-layered system of government policies and financial institutions. While it is a banking platform encouraging people to remit their savings, it also involves all the commercial implications that come with mobile phone ownership, sharing and charging systems. This dimension of the change processes indicates that an investment in services alone does not pay off. On various levels, M-Pesa has appeared as a double-edged sword, on the one hand liberating women financially but on the other, encouraging fraudulent activities and mischief. Both inclusion and exclusion elements are embedded in this process, but most attention has been given to the element of inclusion.

The emergence of ICT-based services cannot abolish the contradictions between urban and rural conditions. The digital divide or 'digital poverty' in the country - situations in which people either cannot afford an ICT service or lack the skills to use one (Obijiofor, 2015) - is a complex phenomenon. Attempts to balance contradictions, such as the establishment of the Huduma Centre system, may even create irritation (Focus groups, November 2015). Huduma Centres operate well in county capitals, but villages can be remote from these. The coming of this improved service creates bitterness among those who are not privileged to share its benefits. Well-educated urban dwellers are included, while the rural poor remain on the fringes of the new service.

If scrutinised more in detail, the main objectives and arguments around ICT policies resemble the declarative style of ITU, UNESCO and other international actors dealing with ICT issues. This supports Florence Etta's (2005) claim that African societies do not properly domesticate their social goals. The ICT sector clearly demands huge amounts of external funding, and Kenyan actors have to take into account what 'sells' well among donors. Funding for education does this but so might freedom of expression, especially among public international supporters of it. Externally funded ICT programmes may not recognize Kenyan sensitivities about freedom of expression. Unfettered social media campaigns may ignite social unrest. ICT programmes that look good from outside the country may actually trigger problems inside it. The Kenyan authorities are careful about this; the social unrest of past years is well remembered. On the other hand, decision-makers might have inherited an oversized social memory of unrest and disorder, and hence, for example, ICT has been kept separate from media policies.

Again, macro and micro dichotomies can be perceived. ICT has increased the volume of servicebased information, but firm control remains over how information is used. Society is willing to open ICT doors only to the service dimension. A further issue is whether policy directives alone will be able to control freedom of expression when the volume and flow of information within society increases. 


\section{Media: Technology changes voices}

Levi Obijiofor (2015, pp. 78-80) has proposed that the emergence of new technologies has not helped African public service media. Globalization and new technology have resulted in a deregulated market that has spawned greater competition and multiple platforms for news production and delivery to consumers. The case of Kenya is complicated, but it follows this formula. In principle, digital migration would allow the introduction of county radio and television, but Kenya does not have a strong tradition of public media with a mandate to offer content for public interest. The Kenya Broadcasting Corporation (KBC) is burdened with successive decades of political interference and poor management. Today, $\mathrm{KBC}$ is required to compete on an equal footing with commercial stations. As a result, content that strictly serves the public interest has been put aside (Interrogating Public Service Media, 2016). The inclusion factor has so far been weak.

On the other hand, commercial companies are not eager to change their programming criteria. While the emergence of ICT-based channels has driven both regulators and media practitioners in the industrialised West to recognize the local as something that deserves special consideration (Ali, 2017, pp. 6-29), such a tendency is not found in Kenya. This may be due to the tradition that journalism has historically been strongly capital-city oriented, and local-area focussed journalism is easily suspected of bringing ethnic contradictions to the fore. Although the number of media channels has grown, the inclusion factor is not prominent among media producers. The online pages of any media institution are not conspicuously inclusive, and although they would welcome an increase in audience numbers, people in poor rural areas are not a tempting target audience for either the public or private media.

The choice of available media has grown, channels have multiplied, and radio listening has to a large extent moved from radio sets to mobile phones. The process continues, and the outcome is not yet clear. However, one conclusion can be drawn. Attempts to maintain ethnic balance and strengthen national unity seem to become more and more difficult, at least in the field of broadcasting. The growth of big, strong radio stations has stopped, while small vernacularlanguage stations grow in popularity. At the same time, television, with its middle-class values, is getting more and more space in urban settings and new local-language television stations are starting, thanks to digital transmission.

The situation is fascinating, and the outcome is not clear. Media institutions are not strongly motivated to strengthen inclusion, but inclusion is promoted by technological changes, especially among the youth. At the same time, community-based media choices are at least partly mediated by individual choices. However, genuine, inside the community born community media with a broad participatory agenda are rare. Many local media are distinctly linked to ethnic interests.

$--$

\section{Social media: A promise or a change agent?}

Online services have started well in Kenya, although the private sector seems to be more active in locating new business options than the public sector, which has more limited funds. The research evidence about the impact of social media, especially among the youth in Kenya, is intriguingly contradictory. Some authors (e.g. Mäkinen \& Kuira, 2008) have noted that the social media were 'not innocent' in the demonstrations after the 2007 elections. The authors believe that social media functioned as alternative media for citizens to promote democratization, although violence 
took over in the unrest and all paths to democratic participation were dramatically cut off. Otieno and Mukhongo (2013) concluded that social media provide a possibility for social mobilization and alertness, especially for Kenyan youth. On the other hand, these early experiences of the use (or misuse) of social media in fact operate against its general acceptance, not only among those in power. Ordinary people also remember the bloody violence.

While assessing social media in Kenya, some researchers (e.g. Wynche et al., 2013) emphasize infrastructure problems, local market constraints and unreliable electricity in villages, but even more, the 'demands of persistent poverty' and based on it, the lack of real online participation. Using Facebook makes a person feel 'advanced,' but the cost factor makes Facebook a rarity; often interviewees seemed to exaggerate their use of it. Facebook has become a marker of social prestige. According to the authors, there was no space left for participation and mobilization through the Internet. They believe that Facebook might develop into a useful gadget for smallscale business but not genuine participation. In short, digital poverty stands as a hindrance to inclusion.

In focus group discussions with Moi University students, many participants admitted that their social media use created disagreements and fights when they visited home. Although they might use a smartphone similar or even identical to their parents' phone, they used it in a different way. The liked 'hanging' on online sites and chatting with their pals in Facebook, while their parents used their phone only for short calls, occasional SMS messages and M-Pesa. The time spent with social media - being present but mentally 'away' - seemed to especially irritate their parents. Some students also said that they had been recruited to demonstrations about tuition fees organized through Facebook groups. The 'Nairobi unrest' (mentioned above) did not interest these students living in Eldoret, but they were aware of it (Focus groups, November 2015). The inclusion/exclusion dimension took a different profile here in the grassroots experience.

Njorore's study (2013) gave similar results. She found that Facebook and WhatsApp were the favourites of the students who participated in her survey. They appreciated the freedom of choice which the social media gave and the rapidity of contacts available, but they also had mixed feelings about spending extensive time with social media. They felt that the time spent with social media could be considered by others, and partly also themselves, as a waste of time or laziness, preventing people from reading books and studying properly.

In case studies about the role of social media in 'Occupy Wall Street' and the Arab Spring (Sorochan, 2016; York, 2016), the contradictions involved are discussed more generally. The authors emphasize that to develop genuine participatory democracy, education in democratic attitudes as well as practical skills are necessary. Without this, many forms of digital communication become selectively inclusive, creating new digital elite groups. From this perspective, the Kenyan government's emphasis on digital education is very relevant as a longterm plan, although its goals seem to stress skills rather than democratic values. But as a shortterm solution, social media alone hardly increase democracy. The researchers suggest that with social media alone, political changes are not possible; fundamental economic transformation is needed (Sorochan, 2016, pp. 24-26). If online participation is elevated as a central principle of a movement's politics, this participatory complex may actually stand in the way of democratic practice.

\section{Media ecology: Community turning into a puzzle}


There is a difference between a conventional rural community and an assemblage constellation, a village with new avenues opened by the smartphone. Both are bottom/up structures, but a community is built on cultural ties developed over time, strengthening stability and resistance to change, while an assemblage is characterized with mobility and fluidity. Thus, a system of values, hierarchies and inherited traditions is challenged, mixed with 'new' problems brought by individualised behaviour. Continuities are breaking or turning fragile. Accordingly, the fears felt by decision-makers are to a certain extent justified or at least understandable. From the perspective of those in power - the ones pushing the ICT boom -- the communities become less controllable.

As in many other African countries, Kenyan society has several social orders, one on top of the other. Like an American sandwich, these layers are colourful and multiple, but they hardly touch each other and follow different sets of social rules. It is perhaps justified to say that Kenya is more a state than a nation, distinctly a top/down society, reasonably effective but distant for the individual citizen. The connectivity aspect of ICT development does not seem to have changed the situation. Citizens still get most of their social support from the sphere of locality and traditionbased conventions. However, this very sphere has remained on the fringes of recent ICT related developments, outside the public attention.

The ICT hub ideology and its implementation have touched the layers of social order in different ways, while those promoting the ICT policies have viewed the ICT hype as a separate, distinguishable dimension of social development, not causing changes in other basic power relations. But parts and wholes are clearly changing positions, thus indicating that assemblage has snatched a space in Kenyan society today. There are several indicators of assemblage and the dynamic rotation of parts and wholes in society.

First, the speed of changes caused by ICT related processes varies. The more technically oriented changes promote fast movement, while the socio-cultural norms change slowly. The ICT phase has brought unpredictable future social developments. Thus, a balanced media ecology is not easy to reach in a society which appreciates social stability to the extent of being ready to limit individual freedoms when it feels the need.

Both the state-supported ICT projects and the media are expanding their services and reaching larger groups than ever before, and this process is strengthening. Superficially, public projects seek the common good, while the private media may be assumed to develop their practices based on market interests. However, the division is not that simple. Public projects are often dependent on outside financing and thus represent compromises; genuine Kenyan priorities might be put aside. In the media sphere, public and private media do compete, and this situation is present in many ICT-based solutions, often promoting compromises.

On both sides, the process to date resembles ICT adoption in many other countries, giving support to Etta's (2005) views. Domestication remains limited, although public implementers might be more favourable towards home-made solutions today. For example, in Kenya the Swahili language is a national glue countering ethnic contradictions, and it could be promoted in journalism and the services branch. With the exception of radio, it has been given little attention in present-day developments. The slow but clear expansion of Swahili in society is tolerated but not promoted. Carol Myers-Scotton (e.g. 1971) has shown in her intriguing sociolinguistic studies about African multilingualism, how complicated language choices are not only for decision-makers but also for the social identity of people. In Kenya, all the other vernacular languages are linked to ethnicity 
and accordingly treated with suspicion. However, the broader public favours media which speak their own language. Frequently, the use of a particular language brings with a different, homemade set of news values and vocabulary that invite 'ordinary people' into public matters.

The same applies to locality. Mobile journalists are today able to cover local events in Kenya, but these are not found newsworthy. This phenomenon is difficult for outsiders to grasp because ICT based developments in other countries have brought in a renaissance of localism. However, it becomes more understandable from the standpoint of nation-building, which is still quite fresh in the minds of power-holders. Quite evidently, locality is one of the dimensions of ICT hub development that deserves special attention. Developing services in the rural areas is relevant, but the inclusion of rural residents in democratic processes requires more; it requires attention to the issues found significant by rural communities. Contradictions in the social arena cannot be avoided by mouthing the abstract rhetoric of democracy.

The power base seems unchanged since before the invasion of ICT technologies. The aim of public ICT policies is to intensify information distribution and increase transparency in a wide range of eprojects. During the implementation phases, as long as tribal tensions are mixed with politics, state organs remain extremely sensitive to ethnicity-related issues. Concrete ethnicity-related traditions and the everyday practices of the grassroots tend to escape public attention, as do power relations within households and local networks and between genders and generations. The assumption of policy-makers seems to be that improved service structures can be developed without any changes in cultural conventions. This appears to be impossible, as Komen's (2015, 2016) studies suggest.

Public and private media institutions are unbending in their practices and value judgments. Many options made possible by improved ICT potential remain unused. For example, the strong urban orientation of news programmes remains dominant, although technically more diversity is possible in journalism. As Peter Dahlgren $(2001$, p. 85 ) has stated, connection with the public involves values, affinity, knowledge, practices, identities and discussion. A medium which has inherited such a complex journalistic mode at least partly reflects these 'firstborn rights', even under a different organisational and technical rule. If the firstborn is a medium that has close contacts with the power elite, it is difficult to alter the status quo.

Perhaps the most fascinating trends in ICT-promoted changes in media use - so far vague and diffuse, but recognizable - are the signs of increased individualization in media culture. Jo HelleValle (2017) quite justifiably emphasizes that media should not be placed in the centre when media use is studied. People's everyday lives should be the point of departure. We should ask how people relate to media. Until now, media use has been a social experience in Kenyan media cultures. Authorities at home have had a say in the way media are used, but the voice of changed technology has been stronger than the government guidance trying to contain it.

Social media can open new avenues of information and participation and is sure to be an essential part of the Kenyan mediascape of the future. For the time being, however, the social media are the most unpredictable element, sharpening contradictions and provoking abrupt changes. The social media have become a new knowledge instrument for new types of elites and especially for youth, thus enabling, at least in the long run, some restructuring of power. But in the short run, social media alone cannot develop a totally new political situation. Hopes of the Huduma Centres' 
power to strengthen citizenry and interest in public matters will take time to realise, if indeed such change will ever be possible.

However, the experience of freedom of expression and mobilisation may spread to a sphere about which society is extremely concerned. Decision-makers as well as ordinary citizens well remember the violence experienced 10 years ago and last autumn. In the future, one-issue movements might shake not only the strongholds of political power but also the shaky ethnic balance, and that very fact might create successive episodes of political unrest. Such a situation would hardly be favourable to freedom of expression. The promotion of the ICT hub has impacted society more deeply than expected by experts. ICT cannot be viewed as a single process separate from politics, culture, tradition and ethnicity. Some of the elements that it brings into the picture appear as worrying, if not frightening in the eyes of both decision-makers and citizens. The only way of meeting the future is by keeping our eyes open and turning the focus to the grassroots. Many hierarchies are shaking because of the assemblage brought by the ICT hype.

\section{Sources:}

Ali, C. (2017) Media Localism. The Policies of Place. Oxfordshire, G.B.: Chicago University Press.

Alias, N.A. et al. (2015) 'Impact of Public Access to Computers and the Internet on the Connectedness of Rural Malaysians'. In Proenza, F. (ed.): Public Access ICT across Cultures. Diversifying Participation in the Network Society. Cambridge, Massachusetts \& London, England: The MIT Press (233-263).

Appadurai, A. (1996) Modernity At Large: Cultural Dimensions of Globalization. Minneapolis: University of Minnesota Press.

Carpenter, E. \& McLuhan, M. (eds.) (1960) Explorations in communication: An anthology. Boston: Beacon.

Chao, N., Yan, G., Li, Y. \& Yao, Q. (2017) 'The internet ecological perception, political trust and political efficacy of Chinese netizens'. Telematics and Informatics 34 (715-725).

DeLanda, M. (2006) A New Philosophy of Society: Assemblage Theory and Social Complexity. London \& New York: Continuum. 
Dahlgren, P. (2001). 'The Transformation of Democracy?' In Axford, B \& R.Huggins (eds.): New Media and Politics. London: Sage (64-88).

Deleuze, G. \& Guattari, F. (2004/1980) A Thousand Plateaus: Capitalism and Schizophrenia. London and New York: Continuum.

Etta, F. (2005) 'Policy Matters: The New Development El Dorado'. In Etta, F. \& Elder, L. (eds): At the Crossroads: ICT Policy-Making in East Africa. Nairobi/Kampala/Dar es Salaam: East African Educational Publishers (1-15).

Helle-Valle, J. (2017) 'Media culture in Africa? A Practice-ethnographic approach'. In Willems, W. \& Mano,W. (eds.) Everyday Media Culture in Africa: Audiences and Users. New York: Routledge.

Innis, H. (1951) The Bias of Communication. Toronto: University of Toronto Press.

Ireri, K. et al (2017) 'First-Level Agenda Setting: a Study of Press vs Public Opinion in Kenya.' African Journalism Studies 38:2-4 (26-49).

Komen, L. (2015) "'Here you can use it". Understanding mobile phone sharing and the concerns it elicits in rural Kenya'. for(e)dialogue. Vol. 1:1 (52-65).

Komen, L. (2016) 'M-Pesa: A Socio-Economic Assemblage in Rural Kenya'. Networking Knowledge Vol. 9: 5 (1-12).

Makinen, M. \& Kuira, M.W. (2008) 'Social Media and Post-Election Crisis in Kenya'. Information and Communication Technology - Africa. Annenberg School of Communication, University of Pennsylvania.

Mapping Digital Media: Kenya. Country report. Open Society Foundations (2013) Open Society Media Programme.

Myers-Scotton, C. (1971) Choosing a lingua franca in an African capital. Edmonton: Linguistic Research.

Njoroge, R. (2013) Impacts of social media among the youth on behavior change: A case study of university students in selected universities in Nairobi, Kenya. Master's thesis, University of Nairobi.

Obijiofor, L. (2015) New Technologies in Developing Societies. From Theory to Practice. Basingstoke, England \& New York: Palgrave.

Obijiofor, L. \& Murray, R. \& Singh, S.E. (2017) “Changes in journalism in two post-authoritarian non-Western countries". The International Gazette 79: 4 (379-399).

Ogola, G. (2015) 'Social media as a heteroglossic discursive space and Kenya's emergent alternative/citizen experiment'. African Journalism Studies 26:4 (66-81).

Otieno, A.C.M. \& Mukhongo, L.L. (2013) 'Social media and youth interest in politics in Kenya.' In Olorunnisola, A. \& Douai, A. (eds.): New Media Influence in Social and Political Change in Africa. United States: IGI Global (273-284). 
Packer, J. \& Wiley, S. (2012) Communication Matters: Materialist Approaches to Media, Mobility, and Networks. New York and London: Routledge.

Phillips, J. (2006) 'Agencement/Assemblage'. Theory, Culture \& Society 23: 2-3 (108-109).

Proenza, F. (2015)'Public Access Impact and Policy Implications'. In Proenza, F. (ed.): Public Access ICT across Cultures. Diversifying Participation in the Network Society. Cambridge, Massachusetts \& London, England: The MIT Press (375-418).

Shao, P. \& Wang, Y. (2017) 'How does social media change Chinese political culture? The formation of fragmentized public sphere'. Telematics and Informatics Vol. 34 (694-704).

Sorochan, C. (2016) 'Participation as Ideology in Occupy Wall Street'. In Barney, D. \& al. (eds.): The Participatory Condition in the Digital Age. Minneapolis \& London: University of Minnesota Press (21-41).

State of the Media in Kenya 2014. Uncertainty, resistance \& change. (2015) Nairobi: Media Policy Research Centre.

Turner, V. (1974) Dramas, Field and Metaphors: Symbolic Action in Human Society. Ithaca, US: Cornell University Press.

Ugangu, Wilson (2015) 'Political Influence and Shifts in Kenya's Media Policy. In Exploring Kenya's Media Policy 1963-2013'. Working paper 1. Media Policy Research Centre, Nairobi.

Wainaina, B. (2008) 'Middle ground'. Kwani? 5:2.

Wynche, S., Schoenebeck, S. \& Forte, A. (2013) 'Facebook is a Luxury: An Exploratory Study of Social Media Use in Rural Kenya'. CSCW 13. February 23-27, 2013.

York, J. (2016) 'From Tunileaks to Bassem Yousef'. In Barney, D. \& al. (eds.): The Participatory Condition in the Digital Age. Minneapolis \& London: University of Minnesota Press (43-58).

\section{Online sources:}

Communications Authority of Kenya

http://www.ca.go.ke/ Retrieved March 26, 2018.

The Digital Learning Programme https://worldteacheraid.org/digital-learning-programme-in-kenya-schools/Retrieved March 21, 2018.

Interrogating Public Service Media Policy Research Centre (MPRC)

http://www.mediapolicycentre.org/interrogating-public-service-media/ Retrieved June 11, 2017.

Ipsos - Synovate Kenya CT. https://www.ipsos.com/ Retrieved June 26, 2017.

The Kenya National ICT Masterplan (2013/14-2017/18)

https://www.kenet.or.ke/sites/default/files/Final\%20ICT\%20Masterplan\%20Apr\%202014.pdf.

Retrieved April 2, 2018. 
Wangari, (2017) 'African Millennials; Mobile Usage and Media Consumption'. GEOPOLL. http://blog.geopoll.com/african-millennials-mobile-usage-and-media-consumption/

Retrieved June 5, 2017.

Interviews (November 2015):

Dr. Katherine Getao, Ministry of Information, Communications and Technology (Nairobi)

Mr. Abner Abaga, ICT Office, Ministry of Information, Communications and Technology (Nairobi)

Mr. John Temba, Head, ICT For Education, Ministry of Education (Nairobi)

Mr. Nganga Wainaina, ICT For Education, Ministry of Education (Nairobi)

Mr. Barnabas Sang Uashin Gishu ICT director (Eldoret)

Ms. Helena Tapper, Programme Manager, GESCI (Nairobi)

Ms. Mercy Kandie, KTN (Eldoret)

Focus group discussions (November 16-19, 2015): 4 groups, total 22 (2 BA, 2 MA student groups) at Moi University, Eldoret, Kenya 